\title{
Kava-based Supplement
}

National Cancer Institute

\section{Source}

National Cancer Institute. Kava-based Supplement. NCI Thesaurus. Code C126793.

A Kava supplement derived from Piper methysticum, with potential cancer preventative activity. Upon oral administration, the kava-based supplement may affect the

metabolism of certain carcinogens, presumably because of the kavalactones present in this product. 